\title{
ORGANIZAÇÃO CURRICULAR DE CURSOS SUPERIORES DE PUBLICIDADE: UM OLHAR BRASILEIRO SOBRE A OFERTA AMERICANA
}

\author{
Curriculum organization of higher education in advertising: A brazilian view \\ about U.S. offering
}

\section{Organización curricular de la educación superior en publicidad: Una mirada brasileña en la oferta estadounidense}

Gino Giacomini Filho ${ }^{1}$

\begin{abstract}
Resumo
O propósito deste artigo é apresentar e discutir a oferta curricular americana para cursos superiores de Publicidade por meio de referencial teórico e estudo de caso com a Boston University e a University of Illinois at Urbana-Champaign. Os resultados apontam que tais ofertas são estruturadas, diferenciadas, e mostram contribuições para a experiência brasileira.
\end{abstract}

Palavras-chave: publicidade, cursos superiores, organização curricular.

\begin{abstract}
The purpose of this article is to present and discusses the curricular offering of higher education in Advertising by means of theoretical reference and case study with Boston University and the University of Illinois at Urbana-Champaign. The results point that those offering are structured, differentiated, and show contributions to Brazilian experience.
\end{abstract}

Keywords: advertising, high education, curriculum organization.

\section{Resumen}

El propósito de este trabajo es presentar y discutir la oferta curricular de cursos de educación superior en Publicidad a través de marcos teóricos y estúdio de caso com la Boston University y la University of Illinois at Urbana-Champaign. Los resultados

\footnotetext{
${ }^{1}$ Doutor e Livre-docente pela ECA/USP. Docente do mestrado em Comunicação da USCS e do curso de graduação da ECA/USP. E-mail: giacomin @usp.br
} 
Organização curricular de cursos superiores de publicidade: Um olhar brasileiro sobre a oferta americana

indican que estas ofertas son estructuradas, diferenciadas, y muestran contribuciones a la experiencia brasileña.

Palabras-clave: publicidad, educación superior, organización curricular.

\section{INTRODUÇÃO}

Vivemos mais um período de reflexão e debates sobre diretrizes curriculares para os cursos superiores (bacharelado) de Publicidade e Propaganda (PP) no Brasil.

Sabe-se que a qualidade dos cursos de PP depende mais do engajamento de alunos, professores e da instituição de ensino superior (IES) do que a estrutura curricular em si, mas insistentemente recai sobre essa última grande foco quando se vislumbram mudanças ou atualização nos projetos pedagógicos.

De fato, é mais simples alterar ou reinventar estruturas curriculares do que fazer com que o corpo docente, discente e a IES cumpram as atribuições legítimas nos planos pessoal, profissional, social, científico, ético e de mercado.

Mas, de qualquer forma, a estrutura ou grade curricular é componente essencial do trabalho pedagógico e será o foco deste estudo. Um dos caminhos para refletir sobre o ensino de graduação em Publicidade no Brasil é valer-se de boas experiências de outros países. Os Estados Unidos podem servir de parâmetro pela liderança que possui no setor da propaganda comercial e pela projeção acadêmica na área publicitária.

Este estudo de delineamento exploratório objetiva apresentar e discutir aspectos da organização curricular que integra cursos superiores de Publicidade nos EUA por meio de estudo de caso acerca das estruturas curriculares dos cursos superiores em Publicidade ofertados pela Boston University e pela University of Illinois at UrbanaChampaign. Portanto, não foi objeto deste trabalho analisar projetos ou propostas pedagógicas integrais, nem a lógica, interdisciplinaridade ou sistemática curricular, mas sim a oferta curricular mediante referencial teórico e estudo de caso com as duas universidades americanas.

\section{UM BREVE OLHAR SOBRE O CONTEXTO DA OFERTA ACADÊMICA PUBLICITÁRIA.}


Organização curricular de cursos superiores de publicidade: Um olhar brasileiro sobre a oferta americana

de Gino Giacomini Filho

A origem do ensino da Publicidade, assim como o próprio setor, não tem marcos claros, embora se trate de uma área com identidade própria e de grande relevância para a sociedade atual. Especula-se que a primeira agência de publicidade tenha surgido no Reino Unido em 1800, mas os próprios anúncios são quase tão antigos quanto a comunicação humana.

No Brasil, por exemplo, a editora Atlas (São Paulo) publicou a primeira edição do livro "Publicidade e Propaganda", de Ernani Macedo de Carvalho, em 1935, porém outros livros já haviam sido publicados no Brasil contemplando a publicidade como um todo e em áreas específicas, como comunicação visual e redação comercial. Os EUA registravam, por exemplo, a obra "Ready made advertisments.", de George Rowell (New York, G. P. Rowell \& co) com data de 1901 para a edição impressa.

Ross (2006) sugere que o primeiro curso com o título de Publicidade tenha sido oferecido pela New York University em 1905, enquanto em 1921 teria ocorrido o primeiro curso de Publicidade em nível de pós-graduação pela University of Missouri. Mas tanto o autor como outros admitem que conteúdos publicitários já eram ofertados em cursos de administração, marketing e outras áreas, mostrando assim o caráter multidisciplinar da publicidade e da propaganda.

O crescimento na oferta dos cursos superiores de Publicidade no Brasil nas últimas décadas é notório, assim como a própria indústria da propaganda comercial tem se incrementado, em parte pela crescente competitividade, novas tecnologias da comunicação e pelo comportamento do consumidor moderno. A internet, por exemplo, ano a ano se consolida como um dos principais meios de comunicação publicitária.

Mas Piereson (2011) questiona se as IES estão preparadas para oferecer cursos de PP dentro do contexto contemporâneo. Ele considera que as IES são burocráticas, resistentes a mudanças, cuja tentativa de perseguir o mercado esbarra num aluno pouco preparado e professores pouco capacitados para conduzir os conteúdos sintonizados com a realidade. Critica as IES que oferecem conteúdos básicos ao se acomodar com certo nivelamento de alunos, sugerindo que os cursos tenham abordagem científica, tecnológica, personalizada e interdisciplinar.

A interdisciplinaridade é também valorizada por Pasadeos (2000) e Johnson (2000), pois tanto a publicidade possui campos que devem se integrar e se complementar, como a própria área publicitária deve exercitar as interfaces com outras áreas da Comunicação e ciências como um todo. Pasadeos sustenta que muitos cursos 
Organização curricular de cursos superiores de publicidade: Um olhar brasileiro sobre a oferta americana

de Comunicação tais como Publicidade, Jornalismo, Relações Públicas podem compartilhar disciplinas como ética, pesquisa e legislação. Especificamente com Relações Públicas, a Publicidade pode compartilhar todo escopo da comunicação integrada de marketing.

Borges (2002) sugere que antes de se tornar um publicitário, o estudante da propaganda deve ser um comunicador, tendo assim que munir-se de teorias, conceitos e técnicas específicas e externas à Publicidade, não somente fruto de experiências na sala de aula, mas também em laboratórios e outros ambientes.

Johnson (2000) estimava em cerca de 350 o número de faculdades que ofereciam curso de Publicidade nos EUA, cerca do dobro que possuía o Brasil no mesmo período (DURAND, 2006). Enquanto o mercado publicitário brasileiro movimentou US\$ 16 bilhões em 2011, a indústria da publicidade dos EUA operou com US\$ 149 bilhões no mesmo ano ${ }^{2}$. São indicadores de que a experiência americana pode ser observada quando da organização curricular (grade curricular) de cursos de PP no Brasil.

Professores que ministravam disciplinas em cursos de Publicidade nos EUA (SCOTT et al, 2003) revelaram metodologia e procedimentos diferenciados para a condução curricular, mas evidenciaram os conteúdos culturais, históricos e tecnológicos; ou seja, parece que os aspectos técnicos e profissionais são deixados a cargo do próprio exercício profissional do egresso. Apresentaram desafios pontuais tendo em vista a demanda discente, como o impacto que a publicidade exerce na sociedade. Mostraram preocupações diversas, como direitos de propriedade para uso de material em sala de aula e tamanho das turmas face à necessidade de um ensino mais personalizado e interativo. Um dos professores revelou que sua IES valoriza a participação de professores visitantes no curso para algumas disciplinas, enquanto vários destacaram a necessidade de conduzir as disciplinas dentro de uma estética visual moderna, inclusive no que se refere ao uso de material de apoio enquanto técnica de ensino e interação.

Assim, ao se voltar para a experiência americana na oferta de cursos superiores de PP, muitas situações se mostram similar e outras tantas diferentes da realidade brasileira.

${ }^{2}$ M\&M Global, Londres. Disponível em: http://mandmglobal.com/media-passport. Acesso em 27 jul. 2012. 
Organização curricular de cursos superiores de publicidade: Um olhar brasileiro sobre a oferta americana

de Gino Giacomini Filho

\section{ESTUDO DE CASO COM UNIVERSIDADES AMERICANAS}

Com o propósito de permitir um olhar sobre a oferta curricular de cursos superiores de Publicidade nos EUA, foram selecionadas duas IES como estudo de caso. Além de assinalar a proposição do estudo, como sugere Yin (2005), o estudo de caso precisa apresentar unidades de análise, lógica que une os dados às proposições e critérios para interpretar as constatações. Nesse sentido, além do contexto dos cursos em suas universidades, são apresentadas suas grades curriculares, conjuntos disciplinares, disciplinas, além do conjunto e sequência que amparam as ofertas curriculares (JANSEN, 2004) relativas a 2013.

A interpretação e análise desses elementos conforme o modelo teórico de Yin (2005) foram efetuadas a fim de: a) mostrar a organização curricular das IES; b) apontar inovações, caso de conteúdos ou uso de tecnologias virtuais c) oferecer contribuições para cursos superiores em Publicidade no Brasil. Para concretizar tais intentos, foram observados os websites das duas universidades (itens "a" e "b"). Para conduzir o item "c", além da análise dos websites, foram apresentadas as ementas das disciplinas que se mostraram diferenciadas para cursos no Brasil. Essas "possíveis contribuições" à oferta brasileira amparam-se em uma situação prática fruto deste autor ter feito parte de 43 comissões avaliadoras de cursos de Comunicação (31 comissões especificamente em Publicidade e Propaganda) no Brasil a serviço de comissões de autorização, reconhecimento e renovação de reconhecimento de cursos de Publicidade e Propaganda pelo Conselho Federal de Educação e pelo Conselho Estadual de Educação (São Paulo) no período de 1992 a 2013.

O Education Portal ${ }^{3}$ ao mencionar as dez melhores escolas de pós-graduação americanas na área de publicidade ofereceu ao presente artigo um referencial para lidar com uma amostra significativa de cursos de bacharelado em Publicidade, até porque a oferta da graduação integrada com a pós-graduação sinaliza qualidade para a primeira. As instituições educacionais listadas foram: University of Florida, The University of Texas at Austin, Michigan State University, University of Illinois at Urbana -

\footnotetext{
${ }^{3}$ Education Portal. Disponível em: http://education-portal.com/top_advertising_graduate_schools.html. Acesso em 10 mai. 2013.
} 
Organização curricular de cursos superiores de publicidade: Um olhar brasileiro sobre a oferta americana

de Gino Giacomini Filho

Champaign, Boston University, The University of Alabama, Syracuse University, Webster University, University of Denver, Texas Christian University.

O presente artigo selecionou os bacharelados em Publicidade da University of Illinois e da Boston University por ocuparem uma posição intermediária em termos de quantidade de alunos dentre as IES ranqueadas.

\subsection{University of Illinois}

Seu bacharelado é em Ciência na Publicidade, oferecido pela Escola de Mídia ${ }^{4}$, que reúne os departamentos de Publicidade, Comunicação Rural, Jornalismo, Estudos de Mídia e Cinema. A Escola de Mídia foi certificada pela ACEJMC (Accrediting Council on Education in Journalism and Mass Communications), que dentre nove requisitos avalia a qualidade da oferta curricular.

O Departamento de Publicidade foi criado em 1949, tido como o primeiro no país e introduzido por Charles H. Sandage, conhecido como "pai da educação publicitária".

Não há uma grade curricular fixa. Os conteúdos e disciplinas mudam a cada período do ano (outono ou primavera) e conforme as necessidades do aluno.

O aluno precisa concluir uma média de 15 horas semanais em disciplinas e atividades ao longo de cada ano (quatro anos). São oferecidas disciplinas específicas do campo publicitário tanto na condição de obrigatórias como eletivas. São também oferecidas disciplinas obrigatórias e eletivas de outras áreas da Comunicação (Jornalismo, Relações Públicas, Cinema) assim como Psicologia, Estatística, Economia, Administração (Escola de Artes e Ciências).

\section{Disciplinas obrigatórias em Publicidade:}

Introdução à Publicidade

Métodos de pesquisa em Publicidade

\section{Disciplinas eletivas (cinco) em Publicidade a serem cursadas a partir desta lista:}

Comunicação para o consumidor e públicos

\footnotetext{
${ }^{4}$ University of Illinois at Urbana-Champaign. Disponível em: http://www.media.illinois.edu/about/; http://www.media.illinois.edu/advertising. Acesso em 11 mai. 2013.
} 
Organização curricular de cursos superiores de publicidade: Um olhar brasileiro sobre a oferta americana

de Gino Giacomini Filho

Campanhas clássicas

História da Publicidade

Estratégia e táticas criativas

Análise de audiência

Gestão Publicitária

Contexto social e cultural da Publicidade

Persuasão e consumidor

Disciplinas obrigatórias da Escola de Artes e Ciências:

Estatística

Economia

Marketing

Disciplinas eletivas (duas) da Escola de Artes e Ciências:

Introdução à Psicologia

Introdução à Sociologia

Antropologia num mundo em mudança

Disciplinas eletivas (seis) oferecidas pela Escola de Mídia (Relação completa das disciplinas/tópicos específicos de Publicidade - obrigatórias e eletivas):

Seminários de graduação

Introdução à Publicidade

Introdução a Relações Públicas

Mídias emergentes

Redação em Relações Públicas

Estudos de Publicidade global

Publicidade global

Problemas especiais

Relações Públicas avançadas

Campanhas clássicas

História da Publicidade

Conteúdo de criação

Conceitos criativos I 
Organização curricular de cursos superiores de publicidade: Um olhar brasileiro sobre a oferta americana

de Gino Giacomini Filho

Conceitos criativos II

Inovação em Publicidade

Publicidade multicultural

Métodos de pesquisa publicitária

Análise de audiência

Tópicos especiais em Publicidade

Gestão e planejamento publicitário

Publicidade e sociedade

Persuasão e consumidor

Seminário de estágio (estágio supervisionado)

Projeto Sandage (biografia de Sandage)

Fundamentos da Publicidade

Teoria da Publicidade

Métodos quantitativos em pesquisa publicitária

Pesquisa qualitativa em Publicidade

Publicidade na comunicação

Publicidade e comportamento do consumidor

Plano e decisões publicitárias

Seminários de pós-graduação I

Seminários de pós-graduação II

Projeto profissional

Pesquisa de tese

\subsubsection{Possíveis contribuições em relação às ofertadas no Brasil}

(Muitas necessitam de disciplina-requisito; as assinaladas com * necessitam de permissão do colegiado da University of Illinois para serem cursadas):

\section{Campanhas clássicas}

Examina as campanhas publicitárias que tem sido os melhores exemplos no gênero ao longo dos anos. Inclui grandes obras concebidas de acordo com os princípios publicitários. 
Organização curricular de cursos superiores de publicidade: Um olhar brasileiro sobre a oferta americana

de Gino Giacomini Filho

Persuasão e consumidor (Persuasion Consumer Response)

Enfoca o que faz uma mensagem massiva ser persuasiva mediante as teorias da comunicação de massa, teorias de persuasão, processo de informação do consumidor e medidas de efetividade publicitária.

\section{Estudos de Publicidade global*}

Volta-se para a atribuição de créditos em função do aluno fazer campanhas e atividades externas, inclusive em outros países com instituições previamente certificadas para tal.

\section{Publicidade global}

Explora teorias da cultura e comunicação aplicando-as aos assuntos publicitários no contexto da globalização. Por meio de estudo de casos e pesquisa aplicada, desenvolvem-se estratégias para a publicidade tendo em vista audiências locais e globais.

\section{Inovação em Publicidade}

Pretende incrementar o pensamento e ações críticas e criativas na Publicidade tendo em vista as tecnologias, perspectivas digitais e outras mídias inovadoras no contexto da comunicação integrada. Possibilita ao aluno entender como consumidores percebem e processam as mensagens publicitárias digitais, pesquisar questões críticas no comportamento do consumidor digital, aprender como utilizar os meios não digitais no contexto da comunicação integrada, aplicar conhecimentos da comunicação digital nos casos reais de propaganda.

\section{Seminários de Pós-graduação*}

Possibilita aos estudantes de Publicidade a oportunidade de interagir com tópicos significativos mediante uma vasta exploração de teorias, pesquisas, assuntos, tendências e práticas publicitárias. Na sequência, os alunos produzem uma proposta de pesquisa.

\section{Projeto profissional*}

Trata-se de um espaço que serve de especialização ou demonstração de excelência pelo aluno em áreas da Publicidade. 
Organização curricular de cursos superiores de publicidade: Um olhar brasileiro sobre a oferta americana

de Gino Giacomini Filho

No tocante às novas tecnologias virtuais, Illinois não parece dedicar espaço privilegiado além das demandas normais que cada disciplina e atividade merecem. Há uma disciplina específica "Mídias emergentes" e os conteúdos virtuais estão distribuídos topicamente em algumas disciplinas, caso de "Inovação em Publicidade".

\subsection{Boston University}

A "habilitação" em Publicidade (Bacharelado de Ciência na Comunicação) está inserida no curso Comunicação de Massa, Publicidade e Relações Públicas, da Escola de Comunicação.

Como boa parte dos estudantes procede de diversas áreas do conhecimento, há um direcionamento para as áreas correlatas também. O currículo de Comunicação enfoca a pesquisa, redação e desenvolvimento de campanhas.

Os alunos têm a oportunidade de participar do AdLab, o primeiro e maior fullservice júnior (agência júnior) de publicidade no mundo segundo o website da Universidade.

O estudante precisa completar 32 disciplinas, sendo 17 em estudos interdisciplinares ${ }^{5}$. O aluno escolhe as disciplinas tendo em vista um foco de estudo.

\section{Disciplinas obrigatórias em Publicidade:}

Pesquisa em Comunicação de Massa

Redação para Comunicação

Teoria e Processo da Comunicação

Disciplina eletiva (uma) em Publicidade a ser cursada a partir desta lista:

Estrutura e comportamento organizacional

Apresentação Profissional

Design e novas mídias

Persuasão e opinião pública

Leis da Comunicação

\footnotetext{
${ }^{5}$ Boston University. Disponível em: http://www.bu.edu/com/academics/masscomm-ad-pr/advertising/; http://www.bu.edu/com/files/2009/12/mcadpr_curicguide_may252012.pdf; http://www.bu.edu/academics/com/courses/. Acesso em: 10 mai. 2013.
} 
Organização curricular de cursos superiores de publicidade: Um olhar brasileiro sobre a oferta americana

de Gino Giacomini Filho

Disciplinas eletivas (cinco) em Publicidade a serem cursadas a partir desta lista:

Introdução à Publicidade (obrigatória)

Fundamentos do Desenvolvimento Criativo (obrigatória)

Novas e tradicionais estratégias de mídia

Direção de arte

Consumidor e o planejamento publicitário

Soluções estratégicas para marcas [Influências ambientais na propaganda]

Gestão publicitária

Laboratório de Publicidade [AdLab]

Desenvolvimento de portfólio para Publicidade [apenas para a área de criação]

Estágio em Comunicação [mínimo de 15 horas por semana]

Produção de vídeo para Comunicação de Marketing

Criação de vídeo para campanhas

Comunicação integrada de Marketing

Comunicação de Marketing internacional e Relações Públicas

Desenvolvimento estratégico criativo

Design e novas mídias

Redação para multimedia

Disciplinas eletivas (três) escolhidas dentre as oferecidas pela Escola de Artes e Ciências

Disciplinas eletivas (onze) escolhidas dentre as oferecidas pela Escola de Comunicação.

As demais disciplinas são optativas livres a serem escolhidas para completar as 32 disciplinas (128) créditos para integralizar o bacharelado

\subsubsection{Possíveis contribuições em relação às ofertadas no Brasil}

(No geral, muitas necessitam de disciplina-requisito, algumas de permissão do colegiado para serem cursadas e outras também são oferecidas no programa de pósgraduação da Boston University): 
Organização curricular de cursos superiores de publicidade: Um olhar brasileiro sobre a oferta americana

de Gino Giacomini Filho

Apresentação Profissional [Técnicas de apresentação]

Os alunos aprendem os aspectos básicos da apresentação eficaz. Da preparação à avaliação crítica da apresentação. A disciplina é destinada a ajudar alunos a incorporar teorias e recursos para uma comunicação em vários contextos. Usa uma combinação de leitura, discussões, práticas e simulação, com apoio de tecnologia interativa.

\section{Persuasão e opinião pública}

As teorias, estratégias e técnicas de persuasão como meio de formar atitudes e opinião pública. Como as pessoas, empresas, governos e instituições elaboram mensagens e comunicam por meio da imprensa, mídia, Publicidade e Relações Públicas. Determinação e entendimento de crenças, atitudes e valores de grupos e sociedade.

\section{Desenvolvimento de portfólio I e II}

Destinada a estudantes que pretendem trabalhar em áreas criativas da publicidade. Os alunos desenvolvem portfólio de suas atividades para apresentá-las na busca por emprego.

\section{Relações comunitárias}

Exame histórico, teórico e técnico empregado em relações comunitárias. Usando uma abordagem de estudo de caso, os alunos aprendem a selecionar um local para desenvolvimento de ações, realização de auditoria de relações com a comunidade, trabalho com os governos estaduais, locais e federais, e desenvolvimento de relações sólidas com a mídia e com os grupos corporativos e sem fins lucrativos .

\section{Campanha política}

Avaliação crítica de estratégias e táticas em campanhas políticas no ambiente sociopolítico. Os papéis de gestores, consultores, pesquisadores, jornalistas, e outros. Analise do impacto da cobertura da imprensa, propaganda eleitoral e debates junto ao eleitorado.

\section{Técnicas de ensino}

Concebida para formar professores assistentes com estratégias de ensino e uso de técnicas para conduzir disciplinas básicas da graduação em Comunicação. Incrementa a 
Organização curricular de cursos superiores de publicidade: Um olhar brasileiro sobre a oferta americana

de Gino Giacomini Filho

capacidade em conduzir discussões, avaliar progresso do estudante e lidar com situações problemáticas.

A Boston University parece privilegiar as novas tecnologias virtuais em um nível maior que a University of Illinois no processo de oferta curricular para o curso de Publicidade. Dedica espaço específico nas disciplinas: "Design e novas mídias", "Novas e tradicionais estratégias de mídia", "Redação para multimedia". Atribui conteúdos virtuais setorizados em disciplinas como "Teoria e Processo da Comunicação" e "Apresentação Profissional”.

\section{CONSIDERAÇÕES COMPLEMENTARES E SUGESTÕES}

As estruturas curriculares de cursos de graduação em Publicidade dos EUA não podem ser automaticamente transplantadas para o Brasil tendo em vista as diferenças normativas, burocráticas, técnicas e de orientação educacional no Brasil e nas IES brasileiras. Porém as práticas nos EUA podem ser contributivas para a experiência no Brasil.

Ao se analisar os websites dos dois cursos americanos, observou-se que a graduação é oferecida de forma articulada com cursos técnicos, especialização, mestrado e até doutorado. No Brasil, essa situação poderia também ser aplicada, não apenas estabelecendo ligações com cursos técnicos (ensino médio), como também tecnológicos e de pós-graduação, quer seja na mesma IES ou instituição diferente da que sedia o curso de graduação em Publicidade. Essa concepção retira da graduação um caráter isolado, ou seja, coloca-a num contexto de continuidade e integração.

O currículo oferece trânsito ao aluno por diferentes departamentos e escolas na mesma universidade, priorizando uma formação inter e multidisciplinar. A oferta de disciplinas nem sempre é fixa. São ofertadas disciplinas para que o aluno eleja um portfólio mais voltado a seu interesse de formação. Para o caso brasileiro, tal diversidade é viável, mas precisa ser considerada com reservas a fim de não se oferecer um curso fragmentado e com pouca identidade com a área publicitária.

As Universidades estudadas aceitam oferecer créditos para atividades dos alunos externas às salas de aula, inclusive internacionais, principalmente as que possuem aderência com práticas publicitárias. Seria também positivo se os cursos brasileiros 
Organização curricular de cursos superiores de publicidade: Um olhar brasileiro sobre a oferta americana

colocassem professores visitantes para ministrar disciplinas e atividades existentes ou novas de acordo com o estado da arte da Comunicação, a Publicidade, a sociedade e outros contextos que incidem na Propaganda.

As novas tecnologias virtuais não são a base para a oferta dos cursos, mas principalmente a Boston University parece oferecer espaço significativo para tais recursos.

As disciplinas oferecidas pelas universidades americanas estudadas são similares às ofertadas nos cursos de graduação em Publicidade de IES brasileiras. Tendo em vista a realidade social, profissional e de mercado no Brasil, alguns assuntos abordados pela University of Illinois e a Boston University poderiam ser avaliados para possível incorporação na forma de disciplinas, seminários, workshops ou palestras, caso de Campanhas clássicas; Persuasão; Estudos regionais e globais de Publicidade; Inovação em Publicidade; Seminários de pós-graduação; Projetos profissionais; Apresentação Profissional [Técnicas de apresentação]; Desenvolvimento de portfólio; Relações comunitárias; Propaganda setorial [Política e outras]; Técnicas de ensino em Comunicação.

As universidades aqui pesquisadas são particulares. Para fixar uma grade curricular para cursos de Publicidade no Brasil é preciso levar em conta fatores para a plena oferta das disciplinas: caráter público, confessional ou privado da universidade; equilíbrio/proporção entre a formação para o mercado profissional e/ou delineamento social, acadêmico e de pesquisa; formação publicitária generalista ou especializada (vocação da universidade); outros fatores.

Embora a interdisciplinaridade seja importante, é fundamental que um curso de PP que se proponha a oferecer uma formação completa ao aluno, mantenha em sua grade curricular as disciplinas que dão identidade à área publicitária. Tais disciplinas devem contemplar as atividades e funções da publicidade e do publicitário conforme mostram os documentos das entidades representativas no plano profissional: Sindicato dos Publicitários, Associação Brasileira de Anunciantes, Associação Brasileira das Agências de Publicidade, Conselho Nacional de Autorregulamentação Publicitária, Clube de Criação, Central de Outdoor etc.

O caráter exploratório deste artigo convida para que novos estudos não somente aprofundem os aspectos levantados, mas contemplem maior diversidade de universidades do exterior, ou ainda empreender estudos comparativos com as 
Organização curricular de cursos superiores de publicidade: Um olhar brasileiro sobre a oferta americana

de Gino Giacomini Filho

instituições de ensino superior brasileiras que possuem a graduação em Publicidade e Propaganda.

\section{REFERÊNCIAS BIBLIOGRÁFICAS}

BORGES, Ademir. Publicidade e propaganda: juntando teoria e prática. Mediação. Belo Horizonte, n.2, out. 2002: 89-98.

DURAND, José Carlos. Educação e ideologia do talento no mundo da publicidade.

Cadernos de Pesquisa. São Paulo: FGV-EAESP, v.36, n.128, maio-ago. 2006: 433-450.

JANSEN, E.P.W.A. The influence of the curriculum organization on study progress in higher education. Higher Education, v. 47, 2004: 411-435.

JOHNSON, Keith F.; ROSS, Billy. Advertising and Public Relations Education: A Five-Year Review. Journalism \& Mass Communication Educator. N. 55, 2000: 66-72.

PASADEOS, Yorgo. Conflicting Attitudes Toward An Integrated Curriculum: IMC instruction may be easier said than done. Journalism \& Mass Communication Educator, v. 55, n. 1: 73-78, mar. 2000.

PIERESON, James. What's wrong with our universities? New Criterion. V. 30, n.1, set. 2011: 17-25.

ROSS, Billy. Advertising Education: yesterday, today, tomorrow. Lubbock: Advertising Education Publications, 2006.

SCOTT, Linda et al. Roundtable on Teaching about Advertising: Thoughts and Experiences. Advertising \& Society Review. V. 3, n. 3/4, 2003.

YIN, Robert K. Estudo de caso: planejamento e métodos. Porto Alegre: Bookman, 2005

Artigo submetido: 25/03/2014

Artigo aprovado: 19/06/2015 